\title{
Komposisi Spesies Capung (Odonata) di Kawasan Cagar Alam Mandor Kecamatan Mandor Kabupaten Landak Kalimantan Barat
}

\author{
Ayu Seftia Nur Wulandari ${ }^{1}$, Tri Rima Setyawati ${ }^{1}$ Kustiati $^{1^{*}}$ \\ ${ }^{1}$ Program Studi Biologi, Fakultas MIPA, Universitas Tanjungpura, Jl. Prof. Dr. H. Hadari Nawawi, Pontianak \\ *Email:kustiati@fmipa.untan.ac.id
}

\begin{abstract}
Dragonfly is one of the predatory insect that can be used as an environmental bio-indicator. Mandor Nature Reserve forest area, which has $3.080 \mathrm{Ha}$, had changed due to illegal logging and illegal gold mining (PETI) giving a sustainable impact on its flora and fauna. This research aim was to determine the species of dragonfly found in the Mandor Nature Reserve area. The sampling was conducted in one month with the Purposive Random Sampling method. Adult species were collected fortnightly by using sweep nets. There were 182 individuals belonged to 2 suborders, 3 families, 11 genera, and 12 species of dragonflies found in Mandor Nature Reserve area. Two suborders are Zygoptera and Anisoptera, the three families are Coenagrionidae, Gomphidae and Liebellulidae. The most common species found of dragonflies is Cerinorubellum ceriagrion (33 individuals or 18\%) and Nannophya pygmaea (29 individuals or 16\%), Orthetrum sabina (23 individuals or $13 \%$ ) and the least common dragonfly is Periagrion microcephallum (4 individuals or $2.16 \%$ ).
\end{abstract}

Keywords: Odonata, dragonflies, Mandor Nature Reserve, bio-indicator

\section{PENDAHULUAN}

Capung merupakan salah satu serangga predator yang berperan sebagai indikator perubahan lingkungan. Nimfa capung tidak dapat hidup pada perairan yang tercemar dan tidak memiliki vegetasi. Hal ini yang menjadikan capung sehingga dapat digunakan sebagai bioindikator lingkungan (Watson \& O'farell, 1991). Lingkungan akuatik sebagai tempat perkembangbiakan capung yang berubah akan menyebabkan keragaman spesies capung menurun. Perubahan habitat tersebut dapat terjadi akibat adanya aktivitas manusia (Patty, 2006).

Cagar Alam Mandor dengan luas $3.080 \mathrm{Ha}$ merupakan kawasan konservasi yang terletak di Kabupaten Landak Provinsi Kalimantan Barat (BPS, 2014). Kawasan hutan CA Mandor mengalami perubahan karena aktivitas manusia seperti pembalakan liar dan penambangan emas tanpa ijin (PETI). Aktivitas tersebut memengaruhi keberadaan dan keberlanjutan flora seperti pohon merbung/mabang (Shorea pachyphylla), agatis (Agathis bornensis), kantong semar (Nepenthes sp.), angrek hitam (Cologyne pandurata), angrek kuping gajah (Bulbophylum beccarii),dan anggrek tebu (Gramotophyllum grama). Selain itu juga berpengaruh pada keberadaan dan keragaman fauna seperti musang (Viverriae), landak (Hysterix sp.), burung ruai (Argusianus argus), elang bondol
(Heliastur indus), kupu-kupu (Lepidoptera), kumbang (Coleoptera), capung (Odonata) dan hewan Avertebrata lainnya yang terdapat di kawasan CA Mandor (Mongabay, 2014).

Data tentang keberadaan dan keragaman jenis capung belum banyak dilakukan di Kalimantan Barat khususnya CA Mandor. Oleh karena itu, penelitian mengenai ragam jenis capung di Kawasan CA Mandor perlu untuk dilakukan.

\section{.BAHAN DAN METODE}

\begin{abstract}
Waktu dan Tempat Penelitian
Penelitian dilaksanakan di Kawasan Cagar Alam Mandor dari 25 November hingga 25 Desember 2017. Pengambilan sampel dilakukan dua kali masing-masing selama satu minggu dengan interval waktu dua minggu antara pengambilan pertama dan kedua. Waktu sampling dilakukan pada pagi hari pukul 08.00-12.00 WIB dan sore hari pukul 13.00-16.00 WIB, karena capung aktif bergerak mencari makan pada pagi dan sore hari sehingga capung lebih mudah untuk diamati. Identifikasi sampel dilakukan di CA Mandor dan di Laboratorium Zoologi Fakultas Matematika dan Ilmu Pengetahuan Alam Universitas Tanjungpura Pontianak.
\end{abstract}




\section{Deskripsi Lokasi Penelitian}

Cagar Alam Mandor terletak di Desa Mandor, Kecamatan Mandor, Kabupaten Landak, Kalimantan Barat. Cagar Alam Mandor (CA) secara administrasi memiliki luas 3.080 ha. CA Mandor terletak pada koordinat $00^{\circ} 15^{\prime}-00^{\circ} 20^{\prime} \mathrm{LU}$ dan $109^{\circ} 18^{\prime}$ - $109^{\circ} 23^{\prime}$ BT (BPS,2014). Keadaan topografi di CA Mandor umumnya datar dan berupa dataran rendah dan perbukitan. Kawasan Cagar Alam Mandor merupakan kawasan hutan lindung dan terdapat areal pertambangan emas (PETI) yang dilakukan oleh masyarakat sekitar sehingga menyebabkan kerusakan di beberapa bagian CA Mandor.
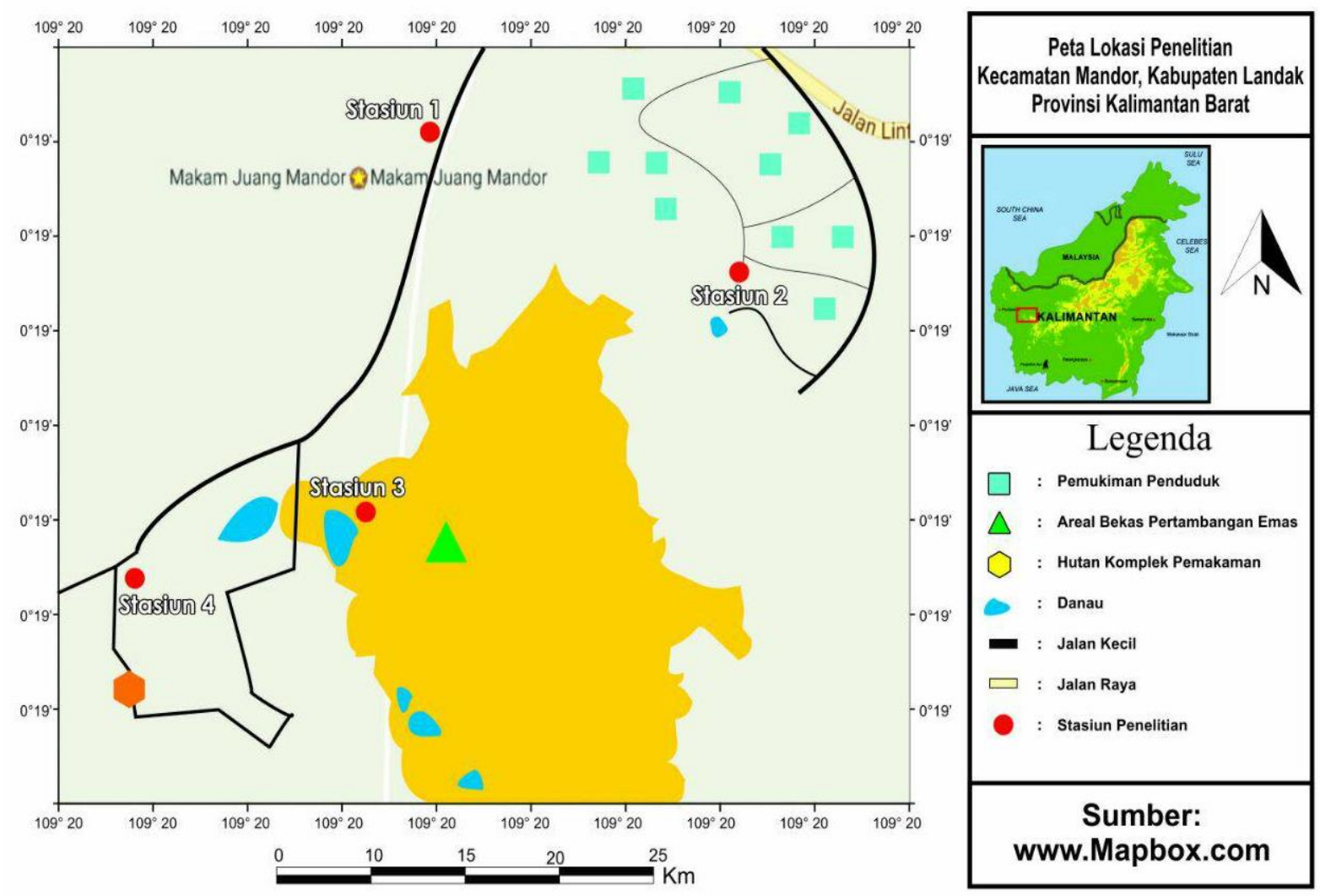

Gambar 1 Peta Stasiun Penelitian

\section{Pengambilan Sampel}

Pengambilan sampel dilakukan pada empat stasiun yang ditentukan dengan menggunakan metode purposive random sampling berdasarkan keberadaan aliran air dan rawa. Sampel capung ditangkap menggunakan jaring serangga. Capung yang tertangkap kemudian dipreservasi dengan cara ditusuk dengan batang rumput dari ujung abdomen hingga thorak sagar tidak patah. Sampel capung selanjutnya dimasukkan kedalam kertas papilot (kertas minyak yang dibentuk segitiga) dan dimasukkan kedalam plastik untuk dibawa ke laboratorium.

\section{Preparasi dan Identifikasi Sampel}

Sampel capung dari lapangan kemudian direntangkan sayapnya dan ditusuk menggunakan jarum pentul kecil pada bagian thoraks. Selanjutnya sampel difoto dan dicatat ciri morfologi dengan melihat warna, bentuk tubuh, bentuk dan posisi sayap kemudian diberi label kode spesies. Kegiatan identifikasi dilanjutkan dengan beberapa pengukuran terhadap spesimen seperti panjang tubuh dan abdomen, panjang sayap depan dan sayap belakang, rentang sayap, bentuk dan warna mata, bentuk dan warna thoraks, warna abdomen dan bentuk venasi sayap. Sampel kemudian diidentifikasi dengan menggunakan buku Susanti (1998), Kalkman \& Orr (2003), dan (Orr, 2005).

\section{Pengukuran Parameter Lingkungan}

Pengukuran parameter lingkungan pada penelitian ini meliputi pengukuran suhu udara, kelembaban udara, kecepatan angin, dan intensitas cahaya.Suhu udara diukur menggunakan termometer yang digantung pada cabang pohon sekitarstasiun penelitian. Kelembaban udara diukur menggunakan higrometer yang diletakkan \pm 1 meter di atas permukaan tanah. Pengukuran kecepatan angin menggunakan anemometer dengan cara mengangkat alat kearah angin yang berlawanan. Intensitas cahaya diukur menggunakan lux meter 
dengan cara mengarahkan sensor cahaya pada area yang akan diukur.

\section{HASIL DAN PEMBAHASAN}

\section{Hasil}

Capung yang terdapat di Kawasan Cagar Alam Mandor Kabupaten Landak Kalimantan Barat sebanyak 182 individu yang termasuk dalam dua subordo yaitu Subordo Zygoptera dan Subordo Anisoptera. Subordo Anisoptera terdiri dari dua famili, yaitu Libellulidae dan Gomphidae, masingmasing meliputi sembilan spesies sebanyak 134 individu dan satu jenis spesies sebanyak 16 individu, sedangkan Subordo Zygoptera terdiri dari satu famili yaitu Famili Coenagrionidae sebanyak dua spesies masing-masing sebanyak 33 individu dan 4 individu (Tabel 1). Ceriagrion cerinorubellum merupakan spesies yang paling banyak ditemukan dalam penelitian, yaitu berjumlah 33 individu, sedangkan spesies capung paling sedikit ditemukan yaitu Periagrion microcephallum dengan jumlah empat individu (Gambar 1).

Stasiun II merupakan stasiun dengan jumlah spesies capung yang paling banyak ditemukan pada pagi hari maupun sore hari, yaitu masing-masing sebanyak 10 dan sembilan spesies, sedangkan stasiun dengan jumlah spesies capung paling sedikit ditemukan pada Stasiun IV sebanyak tiga spesies pada pagi hari dan empat spesies pada sore hari yang ditemukan di Stasiun III dan IV (Gambar 2).

Tabel 1 Jumlah Capung (individu) yang Ditemukan di Kawasan Cagar Alam Mandor

\begin{tabular}{|c|c|}
\hline Famili dan Spesies & $\begin{array}{l}\text { Jumlah Individu } \\
\left(\sum \text { Ind }\right)\end{array}$ \\
\hline \multicolumn{2}{|l|}{ Subordo Anisoptera } \\
\hline \multicolumn{2}{|l|}{ A. Libelluidae } \\
\hline 1. Brachydiplax calybea & 9 \\
\hline 2. Brachygonia oculata & 10 \\
\hline 3. Nannophya pygmaea & 29 \\
\hline 4. Neurothemis ramburii & 21 \\
\hline 5. Orthetrum sabina & 23 \\
\hline 6. Orthetrum testaceum & 10 \\
\hline 7. Pantala flavescens & 8 \\
\hline 8. Rhyothemis phyliis & 18 \\
\hline 9. Potamarcha congener & 6 \\
\hline$\sum$ Individu & 134 \\
\hline \multicolumn{2}{|l|}{ B. Gomphidae } \\
\hline 1. Ichtinogomphus decoratus & 16 \\
\hline$\sum$ Indvidu & 16 \\
\hline \multicolumn{2}{|l|}{ Subordo Zygoptera } \\
\hline \multicolumn{2}{|l|}{ A. Coenagrionidae } \\
\hline 1. Ceriagrion cerinorubellum & 33 \\
\hline 2. Periagrion microcephallum & 4 \\
\hline$\sum$ Individu & 37 \\
\hline Total Individu & 182 \\
\hline
\end{tabular}




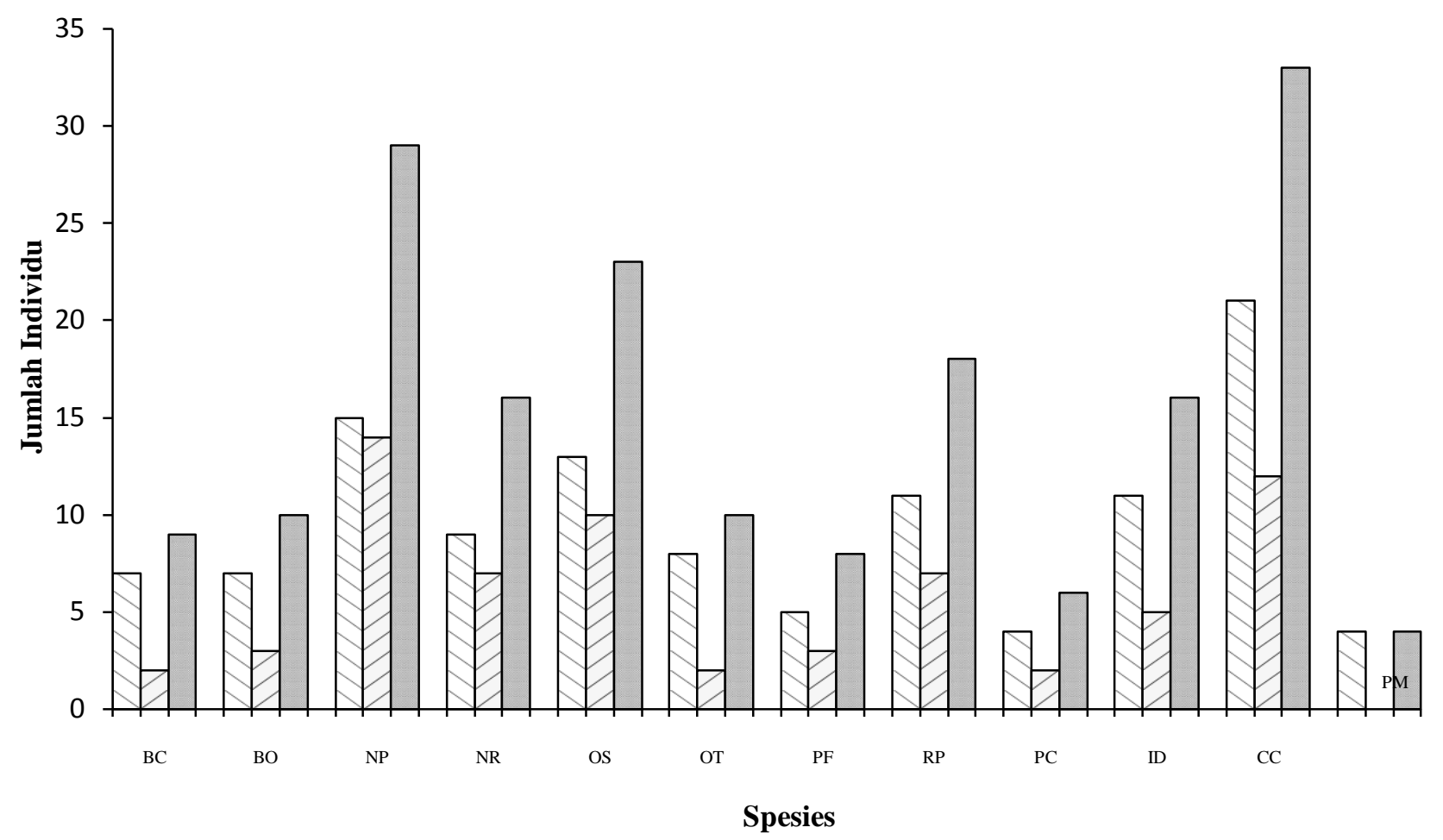

Gambar 1 Komposisi Jumlah Individu Spesies Capung yang ditemukan di Kawasan Cagar Alam Mandor:

$\dashv$ Pagi; $\$ Sore; Total; Famili Libellulidae: Brachydiplax calybea (BC), Brachigonia oculata (BO), Nannophya pygmaea (NP), Neurothemis ramburii (NR), Otrhetrum testaceum (OT), O. sabina (OS), Potamarcha congener (PC), Pantala flavescens (PF), Rhyothemis phyliis (RP); Famili Gomphidae: Ichtinogomphus decoratus (ID); Famili Coenagrionidae: Ceriagrion cerinoruellum (CC), Periagrion microcephallum (PM))

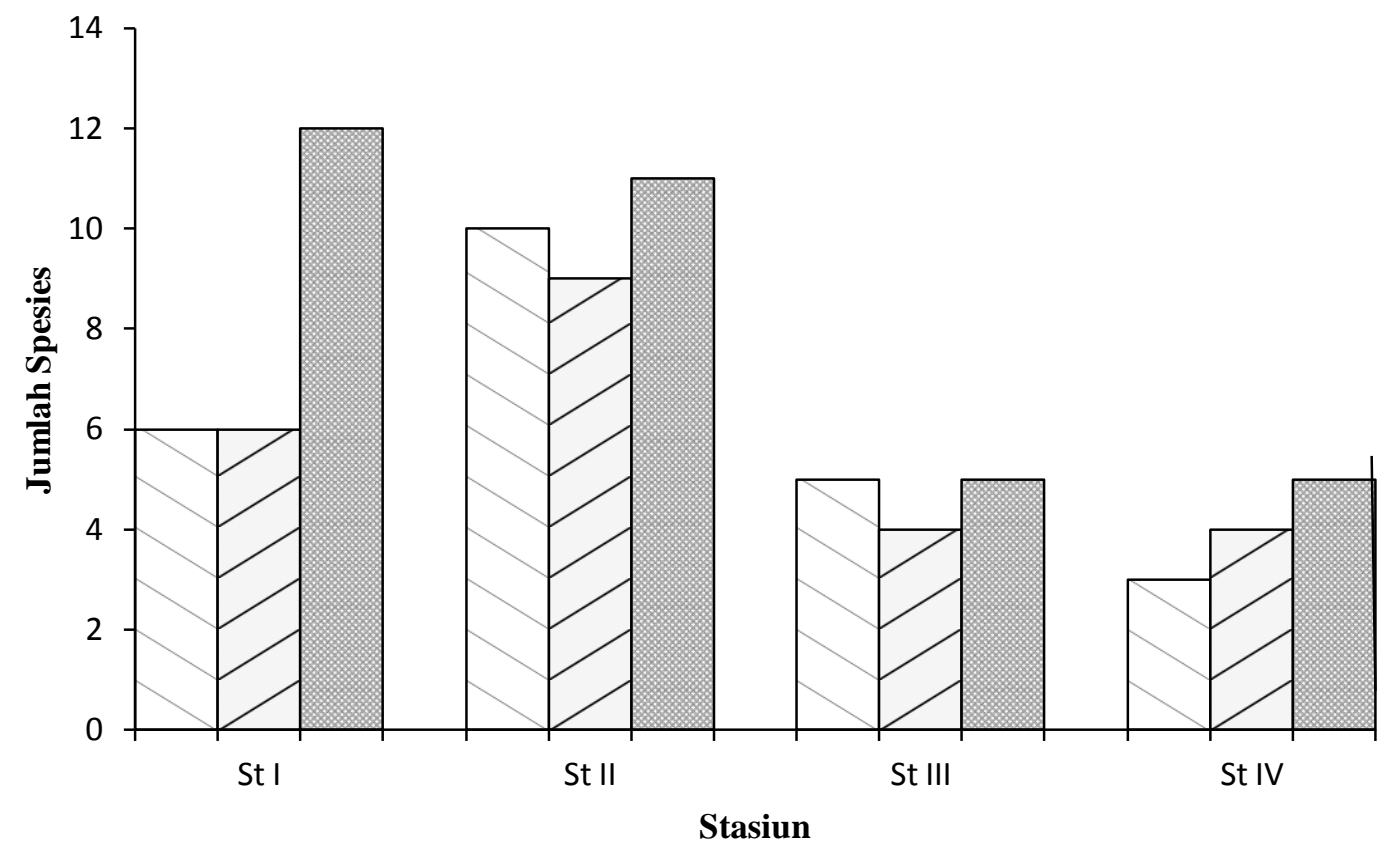

Gambar 2 Komposisi Jumlah Spesies Capung yang ditemukan di Kawasan Cagar Alam Mandor: ( $\mid$ Pagi; $\mid$ Sore; Total 


\section{Pembahasan}

Dua belas spesies capung yang ditemukan di Kawasan CA hanya sebagian kecil atau sekitar 1,6\% spesies capung yang pernah ditemukan dan terdapat di Indonesia (Susanti, 1998) atau sekitar 4,3\% dari 275 spesies capung yang terdapat di Borneo (Sabah dan Semenanjung Malaysia)(Orr, 2003). Sebagian besar spesies capung yang ditemukan berasal dari Famili Libellulidae karena famili ini memiliki jumlah spesies yang banyak dengan sebaran yang luas dan paling mudah beradaptasi.Seperti yang dinyatakan Norma (2012), bahwa Famili Libellulidae merupakan famili dari Subordo Anisoptera dengan spesies terbanyak yaitu \pm 1.000 spesies.Orr (2005), menambahkan bahwa sebanyak 38 genus dan 71 spesies capung anggota Famili Libellulidae tersebar di Borneo.Sebaran yang luas dari Famili Libellulidae diduga menjadi penyebab spesies ini banyak ditemukan di kawasan penelitian.

Jumlah spesies capung yang ditemukan di CA Mandor sama dengan jumlah spesies yang ditemukan di Ruang Terbuka Hijau Kota Pontianak yaitu sebanyak 12 spesies capung (Hartika, 2017). Namun, jumlah tersebut lebih sedikit dibandingkan dengan penelitian capung yang dilakukan oleh Julaika (2018) di Taman Nasional Gunung Palung yaitu sebanyak 15 spesies capung. Spesies capung yang ditemukan di CA Mandor memiliki banyak kesamaan dengan spesies capung di Ruang Terbuka Hijau Kota Pontianak, dari 12 spesies capung yang ditemukan terdapat 6 spesies yang sama dikedua lokasi penelitian tersebut yaitu Neurothemis ramburii, Orthetrum testaceum, Orthetrum sabina, Pantala flavescens, Rhyothemis phyliis dan Periagrion microcephallum. Sedangkan spesies capung yang memiliki kesamaan pada ketiga lokasi penelitian kesamaan yaitu Orthetrum sabina yang termasuk anggota Famili Libellulidae. Menurut Orr (2005), O. sabina merupakan spesies capung Famili Libellulidae yang sebarannya luas dan dapat ditemukan di seluruh Indonesia. Hal ini dikarenakan, capung $O$. sabina memiliki kemampuan beradaptasi pada musim kemarau dan musim hujan serta hidup di semua habitat seperti aliran air dan rawa-rawa yang terdapat banyak Graminae sebagai tempat hinggap $O$. sabina.

Kawasan CA Mandor memiliki beberapa tipe habitat seperti hutan rawa gambut, hutan hujan dataran rendah dan hutan kerangas (Mongabay, 2015). Kondisi hutan pada beberapa tipe habitat di CA Mandor mengalami kerusakan akibat adanya perambahan kawasan untuk aktifitas pertambangan emas (Mongabay, 2015). Hal ini yang memberikan dampak bagi flora dan fauna yang terdapat di kawasan tersebut. Kondisi yang terdapat di CA Mandor berbeda dengan penelitian di Kawasan TNGP yang memiliki kondisi yang masih terjaga. Hal ini dikarenakan kawasan TNGP merupakan kawasan pusat penelitian yang memiliki 8 tipe habitat meliputi rawa air tawar, alluvial, batu berpasir dataran rendah, granit dataran rendah, granit dataran tinggi, rawa gambut, pegunungan, dan habitat kerangas (Susanto, 2012). Sesuai dengan penyataan Primack et al. (1998), yaitu semakin bervariasi habitat suatu daerah maka satwa yang terdapat di dalamnya akan semakin beragam. Sedangkan, sedikitnya jumlah spesies ditemukan di Kawasan CA Mandor dan di RTH Kota Pontianak dapat disebabkan karena berubahnya habitat capung oleh adanya aktifitas manusia (Patty, 2006).

Stasiun I merupakan kawasan tugu monumen yang memiliki areal dan terdapat rawa yang ditumbuhi pohon Akasia dan Pinus disepanjang jalan dan tumbuhan berbunga seperti Alamanda sp. dan Ixora sp., sedangkan Stasiun II merupakan areal pemukiman dengan kolam-kolam ikan dan aliran air yang sama pada Stasiun I. Berdasarkan penelitian, capung yang ditemukan di Stasiun I memiliki kesamaan dengan jenis capung yang terdapat di Stasiun II yaitu Ceriagrion cerinorubellum, Orthetrum sabina, Neurothemis ramburii, Rhyothemis phyliis, dan Ichtinogomphus decoratus, Brachydiplax calybea. Spesies C. cerinorubellum merupakan spesies capung yang ditemukan pada semua stasiun dan paling banyak ditemukan pada Stasiun Idan II yaitu sebanyak 33 individu (18\%). Banyaknya capung $C$. cerinorubellum yang ditemukan di CA Mandor ini diduga karena kondisi faktor lingkungan seperti kecepatan angin berpengaruh terhadap aktivitas capung berukuran kecil (Zygoptera). Kecepatan angin yang terukur di CA Mandor yaitu berkisar $0,3-0,8 \mathrm{~m} / \mathrm{s}$, sesuai dengan pernyataan Gosline (1999), capung menyukai daerah yang memiliki kecepatan angin berkisar $0,2-0,8 \mathrm{~m} / \mathrm{s}$ terutama capung berukuran kecil seperti capung Subordo Zygoptera yang merupakan capung penerbang lemah. Selain itu, kesamaan spesies pada Stasiun I dan II dapat disebabkan oleh aliran air yang sama dan jarak yang dekat antar kedua stasiun.

Spesies capung kedua yang paling banyak ditemukan di Stasiun II adalah Nannophya pygmaea sebanyak 29 individu (16\%). Berdasarkan pengamatan $N$. pygmaea banyak ditemukan di kolam-kolam yang terdapat di Stasiun II dan III. Menurut Yoon et al., (2010), spesies capung $N$. 
pygmaea menyukai perairan yang tidak memiliki arus untuk meletakkan telur-telurnya. Hal ini yang menyebabkan $N$. pygmaea banyak ditemukan pada Stasiun II dan III. Intensitas cahaya yang terukur pada stasiun tersebut berkisar 2833-9447 lux dan suhu udara yang terukur berkisar $30,3-32,6^{\circ} \mathrm{C}$ yang menyebabkan capung $N$. Pygmaea akan hinggap untuk menurunkan panas tubuh sehingga mudah ditangkap pada pengamatan siang hari. Berdasarkan pengamatan, $N$. pygmaea terbang rendah dan hinggap di rumput-rumput Cyperus sekitar kolam. Karakteristik morfologi yang dimiliki $N$. pygmaea adalah memiliki bentuk mata yang besar, gradasi warna mata merah kecokelatan, bagian thoraks dan abdomen berwarna merah. Spesies $N$. pygmaea tersebar luas di Asia tropis-subtropis dan merupakan spesies capung yang terancam punah di Korea sehingga masuk ke dalam daftar IUCN (Yoon et al., 2010). Selain N. pygmaea, spesies capung seperti Orthetrum sabina, Orthetrum testaceum, Pantala flavescens, dan Ceriagrion cerinorubellum ditemukan sama pada kedua stasiun tersebut. Hal ini diduga karena faktor lingkungan pada Stasiun II dan III yang sesuai dengan aktivitas capung seperti berkembang-biak dan mencari makan.

Stasiun IV merupakan areal pemakaman yang ditumbuhi oleh banyak pohon dan memiliki sedikit aliran-aliran air. Capung ditemukan di Stasiun IV adalah Nannophya pygmaea, Neurothemis ramburi, Potamarcha congener, Ceriagrion cerinorubellum dan yang paling banyak ditemukan adalah Brachhygonia oculata sebanyak 10 individu (5\%). Menurut Orr (2003), spesies B. oculata termasuk anggota dari Famili Libellulidae yang merupakan spesies asli (native) yang tersebar di beberapa negara di Asia Tenggara (Brunei Darussalam, Kamboja, Indonesia (Kalimantan, Sumatera dan Jawa), Malaysia dan Thailand) yang memiliki habitat hutan rawa gambut dan alluvial. Ciri-ciri morfologi capung B. oculata memiliki mata berwarna hitam dan merah, thoraks berwarna cokelat-jingga dengan garis berwarna hijau muda disisi lateral, abdomen berwarna jingga, segmen 46 berwarna putih keabu-abuan dan segmen 7-10 berwarna jingga- hitam, abdomen berbentuk silinder pada segmen 10 terdapat embelan (cerci) berwarna hitam (Orr, 2005).

Jumlah individu dan spesies capung yang ditemukan di kawasan CA Mandor diperoleh lebih banyak pada pagi hari dibandingkan dengan jumlah dan spesies capung pada sore hari, sedangkan pada Stasiun IV spesies capung yang ditemukan pada sore hari lebih banyak dibandingkan sore hari. Diduga karena Stasiun IV memiliki banyak naungan pohon yang memengaruhi intensitas cahaya yang masuk pada pagi hari. Hal ini yang menyebabkan perbedaan kebutuhan kondisi lingkungan untuk aktivitas capung pada kedua waktu tersebut. Menurut Klym \& Quinn (2003), pada pagi hari capung memerlukan lebih banyak cahaya matahari untuk menghangatkan tubuh serta memompa venasi sayap untuk persiapan terbang, sedangkan pada sore hari capung telah memiliki cukup energi panas sehingga capung akan bersembunyi di bawah naungan untuk menurunkan suhu tubuhnya. Intensitas cahaya pada pagi hari yang terukur di lokasi penelitian berkisar antara 1095-3833 lux yang lebih hangat dibandingkan intensitas cahaya sore hari yaitu 1953-10850 lux yang cenderung panas. Selain itu, pada saat pengamatan kondisi cuaca pada sore hari cenderung mendung dan hujan ringan. Hal ini yang menyebabkan capung lebih banyak ditemukan pada pagi hari dibandingkan sore hari.

Kondisi faktor lingkungan di kawasan CA Mandor sangat berpengaruh terhadap kehidupan capung mulai dari aktifitas terbang, mencari mankan dan berkembang biak. Faktor lingkungan yang terukur yaitu suhu udara berkisar antara $26,5^{\circ}-31^{\circ} \mathrm{C}$, kelembaban udara yang terukur $70-82 \%$. Intensitas cahaya yang terukur berkisar 1905-9744 lux dan kecepatan angin berkisar 0,2-0,8 m/s. Faktor lingkungan yang terukur masih dalam kisaran normal untuk kehidupan capung. Menurut Susanto (2000), suhu udara sekitar $25^{\circ} \mathrm{C}-29,4^{\circ} \mathrm{C}$ adalah suhu optimal bagi capung untuk beraktivitas dan memompa venasi sayap untuk persiapan terbang. Menurut Jumar (2000), kelembaban udara minimal untuk aktivitas capung adalah $\pm 70 \%$, sedangkan kelembaban udara optimal yang mendukung kelangsungan hidup capung berkisar antara $85-90 \%$ (Moore, 1994). Sehingga kelembaban udara terukur masih dalam kisaran toleransi capung untuk beraktivitas.

\section{UCAPAN TERIMA KASIH}

Terima kasih kepada Balai Konservasi dan Sumber Daya Alam Provinsi (BKSDA) Provinsi Kalimantan Barat yang telah mengizinkan peneliti untuk melakukan penelitian di Kawasan Cagar Alam Mandor dan Weni Julaika yang telah membantu peneliti dalam proses identifikasi sampel penelitian. 


\section{DAFTAR PUSTAKA}

Badan Pusat Statistik, 2017, Letak Geologis Cagar Alam Mandor Kabupaten Landak

Gosline, J,M., Guerette, P,A., Ortlepp, CS dan Savage, K,N., 1999, The mechanical Design of Insect Silk:From Fibrion Sequence to Mechanical Function, Experimental Biology, vol. 202, hal. 3295-3303

Hartika, W, Farah D, dan Wahdina, 2017,'Keanekaragaman Jenis Capung (Odonata) pada Ruang Terbuka Hijau Kota Pontianak', Jurnal Hutan Lestari, vol, 5, no, 2, hal, 156-163

Julaika, W, Junardi dan Kustiati, 2018, 'Spesies Capung (Ordo: Odonata) di Taman Nasional Gunung Palung Kalimantan Barat', Jurnal Exacta, vol. 7, no. 2, hal. 37-42

Jumar, 2000, Entomologi Pertanian, Rineka Cipta: Jakarta

Kylm, M dan M, Quinn, 2003,'Introduction to Dragonfly and Damselfly Watching: Texas Park and Wildlife', Texas Depository Law, this publication is available at the Texas State Publications Clearing house and/or Texas Depository Libraries. Texas 78744

Moore N,W., 1984, Dragonflies as indicator of environmental health. IUCN Species Survival Commissions Newsletter no. 7, vol. 8, hal 984

Mongabay, 2015, diakses 10 Oktober 2018, mongabay.co.id/2015/06/25/Cagar Alam Mandor Kawasan Suaka Alam Rusak Akibat Pertambangan
Norma, R,Y, 2012, Animal of Malaysia: Dargonflies and Damselflies, In: Encyclopedia of Malyasia, Wildlife of Malaysia, 3, 104-105

Orr, A,G., 2003, A Guide to the Dragonflies of Peninsular Malaysia and Singapore, Kota Kianbali, Natural History Publications (Borneo)

Orr, A,G., 2005, A Guide to the Dragonflies of Borneo, Their Identifications and Biology, Kota Kinabalu, Natural History Publications (Borneo)

Patty, N, 2006, Keanekaragaman Jenis Capung (Odonata) di Situ Gintung Ciputat Tangerang, Skripsi, Jurusan Biologi Fakultas Matematika dan Ilmu Pengetahuan Alam, Universitas Islam Negeri Syarif Hidayatullah, Jakarta

Primack, R,B., J, Supriatna, M, Indrawan, dan P, Kramadibrata, 1998, Biologi Konservasi, Yayasan Obor Indonesia, Jakarta, Indonesia

Susanto, P, 2000, Pengantar Ekologi Hewan, Direktorat Jenderal Pendidikan Nasional, Jakarta

Susanto, W,T., 2012, Pola Jelajah dan Pemanfaatan Habitat Orang Utan (Pongo pygmaeus wrumbii) di Stasiun Penelitian Cabang Panti Taman Nasional Gunung Palung Kalimantan Barat, Universitas Indonesia, Thesis

Yoon, J, Nam JM, Kim H, dan Bae YJ, 2010, 'Nannophya pygmaea (Odonata: Libellulidae), an Endangered Dragonfly in Korea, Prefers Abandoned Paddy Fields in the Early Seral Stage: BioOne Research Evolved, Environmental Entomology, no. 39, vol.2, hal.27, hal. 278-285 